\title{
IMPLEMENTASI ALGORITMA BACKPROPAGATION UNTUK MEMPREDIKSI KELULUSAN MAHASISWA
}

\author{
${ }^{1}$ Muhammad Dedek Yalidhan, ${ }^{2}$ Muhammad Faisal Amin \\ 1,2 Program Studi Sistem Informasi, STMIK Banjarbaru \\ Jl. A. Yani KM. 33,3 Loktabat, Banjarbaru, 05114782881 \\ 1dedek.southborneo@gmail.com
}

\begin{abstract}
Student's graduation is one kind of the college accreditation elements by BAN-PT. Because of that. Information System is one of the department in STMIK Banjarbaru, there is no application has been implemented to predict imprecisely of student's graduation time so far, which causes on time graduation percentage tend low every year. Therefore the accurate student's graduation prediction can help the committe to choose the correct decisions in order to prevent the imprecisely of student's graduation time. In this research, the backpropagation algorithm of artificial neural network will be implemented into the application with the output result as delayed and on time graduation. This reseach is using 318 data samples which the $70 \%$ of it will be used as the training data and the other $30 \%$ will be used as testing data. From the calculation of confusion matrix table's the percentage of the prediction accuracy is $98.97 \%$.
\end{abstract}

Keywords: student's graduation, artificial neural network, backpropagation, confusion matrix

\begin{abstract}
Abstrak
Kelulusan mahasiswa merupakan salah satu elemen dalam standar akreditasi perguruan tinggi oleh BAN-PT. Sistem Informasi adalah salah satu program studi yang ada di STMIK Banjarbaru, selama ini belum ada aplikasi yang diimplementasikan untuk memprediksi ketidaktepatan waktu kelulusan mahasiswanya yang menyebabkan angka kelulusan tepat waktu cenderung rendah setiap tahunnya. Oleh sebab itu, prediksi kelulusan mahasiswa yang akurat dapat membantu pihak Program Studi dalam mengambil keputusan-keputusan yang tepat untuk mencegah ketidaktepatan waktu kelulusan mahasiswanya. Pada penelitian ini, artificial neural network algoritma backpropagation diimplementasikan pada aplikasi yang dibuat dengan output lulus terlambat dan lulus tepat waktu. Penelitian ini menggunakan sebanyak 318 sampel data yang mana $70 \%$ data digunakan sebagai data training dan 30 \% data digunakan sebagai data testing. Dari hasil perhitungan tabel confusion matrix diperoleh persentase akurasi prediksi sebesar $98.97 \%$.
\end{abstract}

Kata kunci: kelulusan mahasiswa, artificial neural network, backpropagation, confusion matrix

\section{PENDAHULUAN}

Ada beberapa standar akreditas perguruan tinggi oleh BAN-PT, waktu kelulusan mahasiswa menjadi salah satu elemen dalam standar ke-3 (mahasiswa 
dan lulusan)[1]. Sistem Informasi adalah salah satu program studi yang ada di STMIK Banjarbaru, selama ini belum ada aplikasi yang diimplementasikan untuk memprediksi ketidaktepatan waktu kelulusan mahasiswanya.

Menurut data dari program studi sistem informasi sebanyak 169 mahasiswa baru angkatan 2011 yang lulus tepat waktu hanya berjumlah 29 orang (17\%) [2], menurut BAN-PT persentase KTW 17\% hanya masuk ke dalam harkat dan peringkat CUKUP, dimana KTW $<50 \%$, maka skor $=1+(6 \times \mathrm{KTW})=2$. (dengan deskriptor 4: Sangat Baik, 3: Baik, 2: Cukup, 1: Kurang, 0: Sangat Kurang) [1].

Selama ini pada bagian program studi Sistem Informasi STMIK Banjarbaru belum ada metode yang dapat memprediksi mahasiswa yang akan lulus tidak tepat waktu sejak dini, sehingga pihak program studi tidak dapat membantu mengarahkan mahasiswanya agar lulus tepat waktu.

Jika perguruan tinggi tidak berusaha membantu mengarahkan mahasiwa, maka akan berdampak mahasiswa yang lulus tepat waktu akan berkurang, dikarenakan kurangnya peringatan serta tindakan dini untuk mencegah hal tersebut.

Berdasarkan kondisi tersebut diperlukan penelitian untuk mengolah data yang dimiliki oleh bagian akademik STMIK Banjarbaru. Data yang akan dimanfaatkan di sini adalah data nilai akademik mahasiswa baik yang sudah lulus (untuk data traning dan data testing) maupun yang belum lulus ataupun yang masih menjalani studi yang akan dimanfaatkan untuk memprediksi masa studi masing-masing mahasiswa. Penelitian ini diperlukan karena jika masa studi mahasiswa dapat diprediksi lebih dini, maka pihak program studi maupun mahasiswa yang bersangkutan dapat melakukan tindakan-tindakan yang diperlukan untuk mencegah keterlambatan kelulusan mahasiswa yang bersangkutan sekaligus meningkatkan kualitas program studi itu sendiri.

Ada beberapa penelitian mengusulkan penerapan algoritma backpropagation untuk memprediksi, diantaranya adalah pada penelitian yang dilakukan oleh Rudy Ansari, algoritma backpropagation dengan pengaturan atau parameter awal 12 input, 9 hidden node(neuron) dan 3 output, digunakan untuk memprediksi kelulusan mahasiswa STMIK Indonesia Banjarmasin dan menghasilkan akurasi sebesar 92,49\%. [3] Sedangkan pada penelitian ini akan dicoba pengaturan parameter lainnya guna menghasilkan akurasi yang lebih akurat, karena menurut penelitian yang dilakukan oleh Lestari Handayani dkk. [4] dan Redjeki [5], variabel atau parameter seperti learning rate, goal (total error), fungsi aktivasi dan hidden layer sangat mempengaruhi hasil dari perhitungan algoritma backpropagation.

\section{METODOLOGI PENELITIAN}

\subsection{Kelulusan Tepat Waktu}

Untuk memenuhi capaian pembelajaran lulusan Program Sarjana sesuai dengan Standar Nasional Pendidikan Tinggi, bahwa mahasiswa wajib menempuh beban belajar paling sedikit untuk Program Studi Sistem Informasi sebanyak 145 sks (136 sks mata kuliah wajib dan 9 sks mata kuliah pilihan) yang dijadwalkan 
untuk sekurang-kurangnya 7 (tujuh) semester bagi mahasiswa yang memiliki prestasi akademik tinggi atau 8 (delapan) semester bagi mahasiswa normal. [6]

\subsection{Artificial Neural Network (Jaringan Syaraf Tiruan)}

Artificial Neural Network (Jaringan Syaraf Tiruan) adalah model non-linear yang kompleks, dibangun dari komponen yang secara individu berperilaku mirip dengan model regresi. Jaringan syaraf tiruan dapat divisualisasikan sebagai grafik, dan beberapa sub-grafik mungkin ada perilaku yang sama dengan gerbang logika. Meskipun struktur dari jaringan saraf secara eksplisit dirancang terlebih dahulu, pengolahan bahwa jaringan tidak untuk menghasilkan hipotesis (berbagai gerbang logika dan pengolahan lainnya terstruktur dalam jaringan) berkembang selama proses pembelajaran. Hal ini memungkinkan neuron yang membentuk jaringan akan digunakan sebagai pemecahan masalah dari "program itu sendiri". [7]

\subsection{Algoritma Backpropagation}

Backpropagation merupakan algoritma pembelajaran yang terawasi dan biasanya digunakan oleh perceptron dengan banyak lapisan untuk mengubah bobot- bobot yang terhubung dengan neuron-neuron yang ada pada lapisan tersembunyinya. Algoritma backpropagation menggunakan error output untuk mengubah nilai bobot-bobotnya dalam arah mundur (backward). Untuk mendapatkan error ini, tahap perambatan maju (feedforward) harus dikerjakan terlebih dahulu. [8]

\subsection{Proses Training Backpropagation}

Menurut Fausett [9] berikut ini adalah algoritma pelatihan jaringan propagasi balik untuk satu hidden layer:

a. Inisialisasi bobot dengan memberikan nilai acak (nilai acak kecil - $0.5 \mathrm{~s} / \mathrm{d} 0.5$ ).

b. Selama kondisi berhenti false, lakukan langkah 3-9.

c. Untuk setiap pasangan data pelatihan ( $x_{-}$setb, tb) dimana $b=1, \ldots 1$, lakukan 4-8.

d. Memulai proses forward, setiap unit input (Xi, $\mathrm{i}=1, \ldots, \mathrm{n}$ ) menerima sinyal input xi dan melanjutkannya ke hidden layer, setiap unit tersembunyi $(Z j, j=1, \ldots p)$ menjumlahkan sinyal-sinyal input terbobot,

$$
z_{-i n_{j}}=v o_{j}+\sum_{i=1}^{n} x_{i} v_{i j}
$$

gunakan fungsi aktivasi untuk menghitung sinyal output-nya,

$$
Z_{i}=f\left(Z i n_{i}\right)
$$

dan lanjutkan sinyal ke semua unit di lapisan atasnya (output layer).

e. Setiap unit output $(\mathrm{Yk}, \mathrm{k}=1, \ldots, \mathrm{m})$ menjumlahkan sinyal-sinyal input terbobot,

$$
y_{-i n_{k}}=w o_{k}+\sum_{i=1}^{p} z_{j} w_{j k}
$$


gunakan fungsi aktivasi untuk menghitung sinyal output-nya,

$$
y_{\mathrm{k}}=f\left(y_{-} i \eta_{\mathrm{k}}\right.
$$

dan lanjutkan ke proses backward.

f. Tiap-tiap unit output ( $\mathrm{yk}, \mathrm{k}=1, \ldots, \mathrm{m})$ menerima pola target yang berhubungan dengan pola input pembelajaran, hitung informasi error $\mathrm{k}$,

hitung koreksi bobot wjk,

$$
\delta_{k}=\left(t_{k}-y_{k}\right) f^{\prime}\left(y_{-} i n_{k}\right)
$$

hitung koreksi bias w0k,

$$
\Delta w_{j k}=\alpha \delta_{k} z_{j}
$$

$$
\Delta w o_{\mathrm{k}}=\alpha \delta_{\mathrm{k}}
$$

dan kirimkan nilai informasi error ke lapisan bawahnya.

g. Tiap-tiap hidden unit menjumlahkan hasil kali informasi error dengan Weight.

hitung informasi error j,

$$
\delta_{-i n_{j}}=\sum_{k=1}^{m} \delta_{k} w_{j k}
$$

koreksi bobot vij,

$$
\delta_{j}=\delta_{i n_{i}} f^{\prime}\left(z_{-} i n_{j}\right)
$$

$$
\Delta v_{i j}=\alpha \delta_{i} x_{t}
$$

dan koreksi bias v0j,

$$
\Delta v_{o j}=\alpha \delta_{j}
$$

lanjutkan ke tahap peng-update-an weight.

h. Setiap unit output $(\mathrm{Yk}, \mathrm{k}=1, \ldots, \mathrm{m})$ memperbaiki bobot dan biasnya $(\mathrm{j}=0, \ldots, \mathrm{p})$,

$$
w_{j k}(\mathrm{baru})=w_{\mathrm{jk}}(\mathrm{lama})+\Delta w_{\mathrm{jk}}
$$

setiap unit tersembunyi $(\mathrm{Zj}, \mathrm{j}=1, \ldots, \mathrm{p})$ memperbaiki bobot dan biasnya

$(\mathrm{i}=0, \ldots, \mathrm{n})$,

lanjutkan ke tes kondisi.

$$
v_{i i}(\operatorname{baru})=v_{i i}(\operatorname{lama})+\Delta v_{i i}
$$

i. Tes kondisi, jika true maka training berhenti.

\subsection{Momentum}

Pada standard backpropagation, perubahan bobot didasarkan atas gradient yang terjadi untuk pola yang dimasukkan pada saat itu. Modifikasi yang dapat dilakukan adalah dengan menggunakan momentum yaitu dengan melakukan perubahan bobot yang didasarkan atas arah gradient pola terakhir dan pola sebelumnya yang dimasukkan. Penambahan momentum dimaksudkan untuk menghindari perubahan bobot yang mencolok yang diakibatkan oleh adanya data yang sangat berbeda dengan yang lain. Variabel momentum dapat meningkatkan waktu pelatihan dan stabilitas dari proses pelatihan [10]. Berikut merupakan rumus momentum menurut Fausett [9]: 


$$
w_{i k}(t+1)=w_{i k}(t)+\alpha \delta_{k} z_{i}+\mu\left[w_{i k}(t)-w_{i k}(t-1)\right]
$$

Dan

$$
v_{i j}(t+1)=v_{i j}(t)+\alpha \delta_{i} x_{i}+\mu\left[v_{i j}(t)-v_{i j}(t-1)\right]
$$

Keterangan:

$w_{i k}(t)=$ Bobot mula-mula pola kedua

$\alpha \delta_{k} z_{j}=$ Hasil dari perhitungan langkah ke-6 $\left(\Delta w_{j \mathrm{k}}\right)$.

$w_{i k}(t-1)=$ Bobot mula-mula pada data ke-1 iterasi pertama.

$\mu . \quad=$ Nilai momentum

$v_{i j}(t) \quad=$ Bobot mula-mula pola kedua

$\alpha \delta_{i} x_{i}=$ Hasil dari perhitungan langkah ke-7 $\left(\Delta v_{i j}\right)$.

$v_{i j}(t-1)=$ Bobot mula-mula pada data ke-1 iterasi pertama.

\section{HASIL DAN PEMBAHASAN}

\subsection{Pra Pengolahan}

Sampel data yang akan digunakan sebagai data training adalah $70 \%$ dari total data keseluruhan mahasiswa program studi Sistem Informasi STMIK Banjarbaru tahun angkatan 2011, 2012, dan 2013, terdiri dari data gender, index prestasi semester 1 , jumlah pengambilan satuan kredit semester 2 , index prestasi semester 2, jumlah pengambilan satuan kredit semester 3, jumlah pengambilan satuan kredit semester 4, index prestasi semester 4, jumlah pengambilan satuan kredit semester 5, dan index prestasi semester 5. Sedangkan sampel data yang digunakan sebagai data testing $30 \%$ dari total data keseluruhan mahasiswa program studi Sistem Informasi STMIK Banjarbaru tahun angkatan 2011, 2012, dan 2013.

Alur penelitian pada penelitian ini dimulai dengan proses input dataset yang dilanjutkan dengan pra pengolahan data, yang terdiri dari set role dan normalize. Set Role adalah operator pada tool Rapid Miner untuk mengatur peran yang akan digunakan. Kebanyakan operator klasifikasi tidak akan bekerja jika tidak ada atau bahkan jika ada lebih dari satu atribut dengan peran label di dalam dataset [11] Setelah melakukan set role, kemudian dilakukan normalisasi dataset untuk mengubah semua nilai atribut menjadi kisaran 0-1 dengan menggunakan operator normalize pada tool Rapid Miner.

\subsection{Hasil Uji Coba}

Uji coba dilakukan dengan menggunakan tool Rapid Minner versi 7.6 untuk menentukan parameter Neural Network berupa training cycles, learning rate, momentum, dan hidden layer terbaik bagi dataset pada penelitian ini.

Pada uji coba pertama, percobaan dilakukan untuk menentukan nilai training cycles, nilai training cycles (epoch) dalam penelitian ini ditentukan dengan cara melakukan uji coba memasukkan nilai dengan range 200 sampai dengan 2000 untuk training cycles (epoch), serta nilai 0.1 untuk learning rate dan 0.1 untuk momentum, hasil dari uji coba dapat dilihat pada Tabel 1. 
Tabel 1. Percobaan Penentuan Nilai Training Cycles

\begin{tabular}{llll}
\hline Training Cycles & Learning Rate & Momentum & Akurasi \\
\hline 200 & 0.1 & 0.1 & $97.94 \%$ \\
400 & 0.1 & 0.1 & $97.94 \%$ \\
600 & 0.1 & 0.1 & $97.94 \%$ \\
800 & 0.1 & 0.1 & $97.94 \%$ \\
1000 & 0.1 & 0.1 & $97.94 \%$ \\
1200 & 0.1 & 0.1 & $98.97 \%$ \\
1400 & 0.1 & 0.1 & $96.91 \%$ \\
1600 & 0.1 & 0.1 & $96.91 \%$ \\
1800 & 0.1 & 0.1 & $97.94 \%$ \\
2000 & 0.1 & 0.1 & $97.94 \%$ \\
\hline
\end{tabular}

Training cycles (epoch) dipilih berdasarkan nilai akurasi tertinggi yang dihasilkan. Berdasarkan hasil percobaan di atas, maka dipilih nilai training cycles (epoch) sebesar 1200. Nilai training cycles (epoch) ini selanjutnya dipakai untuk percobaan dalam menentukan learning rate.

Nilai learning rate ditentukan dengan cara melakukan uji coba memasukkan nilai dengan range 0.1 sampai dengan 1 . Nilai training cycles (epoch) dipilih dari percobaan sebelumnya yaitu 1200 , sedangkan nilai 0.1 digunakan untuk nilai momentum, hasil dari uji coba dapat dilihat pada Tabel 2.

Tabel 2. Percobaan Penentuan Learning Rate

\begin{tabular}{llll}
\hline Training Cycles (epoch) & Learning Rate & Momentum & Akurasi \\
\hline 1200 & 0.1 & 0.1 & $98.97 \%$ \\
1200 & 0.2 & 0.1 & $97.94 \%$ \\
1200 & 0.3 & 0.1 & $97.94 \%$ \\
1200 & 0.4 & 0.1 & $97.94 \%$ \\
1200 & 0.5 & 0.1 & $96.91 \%$ \\
1200 & 0.6 & 0.1 & $97.94 \%$ \\
1200 & 0.7 & 0.1 & $97.94 \%$ \\
1200 & 0.8 & 0.1 & $97.94 \%$ \\
1200 & 0.9 & 0.1 & $97.94 \%$ \\
1200 & 1 & 0.1 & $97.94 \%$ \\
\hline
\end{tabular}


Nilai learning rate dipilih berdasarkan nilai akurasi tertinggi yang dihasilkan. Berdasarkan hasil percobaan di atas, dipilih nilai learning rate sebesar 0.1 , nilai ini akan digunakan untuk percobaan dalam menentukan nilai momentum.

Nilai momentum ditentukan dengan cara melakukan uji coba memasukkan nilai dengan range 0 sampai dengan 0.9. Nilai training cycles (epoch) dan learning rate dipilih dari percobaan sebelumnya yaitu 1200 dan 0.1, hasil uji dari uji coba dapat dilihat pada Tabel 3.

Tabel 3. Percobaan Penentuan Nilai Momentum

\begin{tabular}{llll}
\hline Training Cycles (epoch) & Learning Rate & Momentum & Akurasi \\
\hline 1200 & 0.1 & 0 & $97.94 \%$ \\
1200 & 0.1 & 0.1 & $98.97 \%$ \\
1200 & 0.1 & 0.2 & $96.91 \%$ \\
1200 & 0.1 & 0.3 & $96.91 \%$ \\
1200 & 0.1 & 0.4 & $96.91 \%$ \\
1200 & 0.1 & 0.5 & $97.94 \%$ \\
1200 & 0.1 & 0.6 & $97.94 \%$ \\
1200 & 0.1 & 0.7 & $97.94 \%$ \\
1200 & 0.1 & 0.8 & $97.94 \%$ \\
1200 & 0.1 & 0.9 & $96.91 \%$ \\
\hline
\end{tabular}

Berdasarkan hasil percobaan di atas, maka untuk parameter neural network dalam penelitian ini digunakan nilai 1200 untuk training cycles (epoch), 0.1 untuk learning rate, dan 0.1 untuk momentum.

Untuk penentuan jumlah hidden layer dan hidden node, dilakukan uji coba dengan menggunakan satu dan dua hidden layer, sedangkan untuk hidden node digunakan angka dengan range 1 sampai dengan 24. Hasil uji coba untuk satu hidden layer dapat dilihat pada Tabel 4 .

Tabel 4. Percobaan Dengan Satu Hidden Layer

\begin{tabular}{lccc}
\hline Jumlah Hidden Node & Akurasi & Jumlah Hidden Node & Akurasi \\
\hline 3 & $98.97 \%$ & 14 & $97.94 \%$ \\
4 & $97.94 \%$ & 15 & $97.94 \%$ \\
5 & $96.91 \%$ & 16 & $97.94 \%$ \\
6 & $96.91 \%$ & 17 & $97.94 \%$ \\
7 & $97.94 \%$ & 18 & $97.94 \%$ \\
8 & $97.94 \%$ & 19 & $97.94 \%$ \\
9 & $97.94 \%$ & 20 & $97.94 \%$ \\
10 & $97.94 \%$ & 21 & $97.94 \%$ \\
11 & $97.94 \%$ & 22 & $97.94 \%$ \\
12 & $97.94 \%$ & 23 & $97.94 \%$ \\
13 & $97.94 \%$ & 24 & $97.94 \%$ \\
\hline
\end{tabular}


Hasil terbaik pada percobaan satu hidden layer yaitu hidden layer dengan jumlah hidden node 3 yang menghasilkan akurasi sebesar $98.97 \%$.

Untuk dua hidden layer, dilakukan sebanyak 27 arsitektur, hasil percobaan dapat dilihat pada tabel 5 .

Tabel 5 Percobaan Dengan Dua Hidden Layer

\begin{tabular}{lll}
\hline Jumlah Hidden Node Layer 1 & Jumlah Hidden Node Layer 2 & Akurasi \\
\hline 1 & 1 & $97.94 \%$ \\
1 & 2 & $97.94 \%$ \\
1 & 3 & $97.94 \%$ \\
1 & 4 & $96.91 \%$ \\
1 & 5 & $97.94 \%$ \\
1 & 6 & $97.94 \%$ \\
1 & 7 & $97.94 \%$ \\
1 & 8 & $97.94 \%$ \\
1 & 9 & $97.94 \%$ \\
2 & 1 & $96.91 \%$ \\
2 & 2 & $98.97 \%$ \\
2 & 3 & $97.94 \%$ \\
2 & 4 & $97.94 \%$ \\
2 & 5 & $97.94 \%$ \\
2 & 6 & $97.94 \%$ \\
2 & 7 & $97.94 \%$ \\
2 & 8 & $97.94 \%$ \\
2 & 9 & $98.97 \%$ \\
3 & 9 & $96.91 \%$ \\
3 & 1 & $97.94 \%$ \\
3 & 2 & $97.94 \%$ \\
3 & 3 & $97.94 \%$ \\
3 & 4 & $97.94 \%$ \\
3 & 5 & $97.94 \%$ \\
3 & 9 & $97.94 \%$ \\
3 & 9 & $97.94 \%$ \\
3 & 9 & $97.94 \%$ \\
\hline & 5 &
\end{tabular}

Percobaan untuk dua hidden layer tidak menghasilkan akurasi yang lebih tinggi dari satu hidden layer dengan jumlah hidden node 3.

Penentuan jumlah input node dalam penelitian ini ditentukan dengan cara melakukan percobaan sebanyak 3 kali, yang pertama menggunakan 6 input nodes (Gender, IPS1, SKS2, IPS2, SKS3, IPS3), yang kedua menggunakan 8 input nodes (Gender, IPS1, SKS2, IPS2, SKS3, IPS3, SKS4, IPS4), dan yang ketiga menggunakan 10 input nodes (Gender, IPS1, SKS2, IPS2, SKS3, IPS3, SKS4, IPS4, SKS5, IPS5). 
Ketiga percobaan tersebut menggunakan parameter nilai 1200 untuk training cycles (epoch), 0.1 untuk learning rate, hidden layer 1, hidden node 3, dan 0.1 untuk momentum didapatkan hasil akurasi seperti pada Tabel 6.

Tabel 6. Percobaan Jumlah Input Node

\begin{tabular}{ccccc}
\hline $\begin{array}{c}\text { Jumlah Input } \\
\text { Node }\end{array}$ & $\begin{array}{c}\text { Training } \\
\text { Cycles (epoch) }\end{array}$ & $\begin{array}{c}\text { Learning } \\
\text { Rate }\end{array}$ & Momentum & Akurasi \\
\hline 6 & 1200 & 0.1 & 0.1 & $96.91 \%$ \\
8 & 1200 & 0.1 & 0.1 & $97.94 \%$ \\
10 & 1200 & 0.1 & 0.1 & $98.97 \%$ \\
\hline
\end{tabular}

Berdasarkan percobaan di atas jumlah input nodes 10 menghasilkan akurasi paling besar yaitu 98.97, maka pada penelitian digunakan 10 input nodes.

Hasil penerapan neural network ke dalam aplikasi yang dibuat untuk memprediksi kelulusan mahasiswa STMIK Banjarbaru adalah seperti pada Tabel 7.

Tabel 7. Confusion Matrix

\begin{tabular}{lccr}
\hline & $\begin{array}{l}\text { true } \\
\text { Terlambat }\end{array}$ & $\begin{array}{l}\text { true } \\
\text { Waktu }\end{array}$ & Tepat \\
& 95 & 1 \\
pred. Terlambat & 0 & 1 \\
pred. Tepat Waktu & & \\
\hline
\end{tabular}

Dari total keseluruhan data testing yang digunakan sebanyak 97 data, 95 diantaranya mendapat hasil true-positive (prediksi terlambat dan kenyataan terlambat), 1 diantaranya true-negative (prediksi terlambat namun kenyataan tepat waktu), 0 diantaranya false-negative (prediksi tepat wakt namun kenyataan terlambat), dan 1 diantaranya false-positive (prediksi tepat waktu dan kenyataan tepat waktu).

Hasil akurasi dapat didapatkan dengan cara membagikan jumlah prediksi yang sesuai kenyataan (true-positive+false-positive) dengan jumlah data keseluruhan (97) kemudian dikalikan 100.

$$
\text { Akurasi }=\frac{96}{97} \times 100=98.97
$$

\section{SIMPULAN}

Dari hasil penelitian dapat diambil kesimpulan bahwa :

a. Parameter seperti jumlah input nodes, training cycles (epoch) learning rate, momentum, jumlah hidden layer, dan jumlah hidden node dapat mempengaruhi akurasi dari algoritma backpropagation.

b. Karena data training yang digunakan dominan memiliki target terlambat daripada tepat waktu, menyebabkan algoritma yang diterapkan di aplikasi cenderung menghasilkan output terlambat. 
c. Jumlah data training yang digunakan dapat mempengaruhi akurasi dan kerasionalan output algoritma backpropagation.

d. Berdasarkan penelitian yang dilakukan dan hasil dari implementasi algoritma backpropagation pada aplikasi yang dibuat, bahwa faktor yang paling mempengaruhi hasil prediksi adalah index prestasi semester (IPS) mahasiswa yang bersangkutan.

e. Pada proses prediksi dengan menggunakan aplikasi yang telah dibuat, prediksi kelulusan mahasiswa STMIK Banjarbaru dengan menggunakan 97 sampel data angkatan 2011, 2012 dan 2013 didapatkan akurasi sebesar $98.97 \%$.

\section{DAFTAR PUSTAKA}

[1] BAN.PT., "Buku 6-Matriks Penilaian Akreditasi Sarjana", Jakarta: BAN.PT, 2008.

[2] STMIK Banjarbaru, "Laporan Kelulusan Tahun 2015", STMIK Banjarbaru, Banjarbaru, 2015.

[3] R. Ansari, "Prediksi Kelulusan Mahasiswa Dengan Jaringan Syaraf Tiruan", Jurnal Teknologi Informasi Universitas Lambung Mangkurat, vol. 1, pp. 18-23, 2016.

[4] M. A. Lestari Handayani, "Penerapan JST (Backpropagation) untuk Prediksi Curah Hujan", Seminar Nasional Teknologi Informasi, Komunikasi dan Industri, vol. 7, 2015.

[5] S. Redjeki, "Perbandingan Algoritma Backpropagation dan K-Nearest Neighbor untuk Identifikasi Penyakit", Seminar Nasional Aplikasi Teknologi Informasi, 2013.

[6] STMIK Banjarbaru, "Peraturan Akademik", Banjarbaru: STMIK Banjarbaru, 2017.

[7] M. K. Cowan, "Machine Learning”, Standford: Standford University, 2013.

[8] E. Riyanto, "Sistem Pengenalan Pengucap Manusia Dengan Ekstraksi Ciri MFCC dan Algoritma Jaringan Saraf Tiruan Perambatan Balik Sebagai Pengenalnya", Pasca Sarjana Universitas Diponegoro, Surabaya, 2013.

[9] L. Fausett, "Fundamentals of Neural Networks: Architectures, Algorithms, and Applications", Upper Saddle River: Prentice-Hall, 1994.

[10] O. N. AL-Allaf, "Improving the Performance of Backpropagation Neural Network", Journal of Computer Science, vol. 6, pp. 1347-1354, 2010.

[11] R. S. W. Indah Suryani, "Penerapan Exponential Smoothing untuk Transformasi Data dalam Meningkatkan Akurasi Neural Network", Journal of Intelligent Systems, vol. 1, pp. 67-75, 2015. 